\title{
Evaluation of Two Formalin Concentrations During Yellow Perch Egg Incubation
}

\author{
Matthew J. Ward \\ South Dakota Department of Game, Fish and Parks, Blue Dog State Fish Hatchery \\ 44437 139A Street, Waubay, South Dakota, 57273, United States
}

Tel: 1-605-947-4657Ｅ-mail: matthew.ward@state.sd.us

\begin{abstract}
Michael E. Barnes
South Dakota Department of Game, Fish and Parks, McNenny State Fish Hatchery 19605 Trout Loop, Spearfish, South Dakota, 57783, United States
\end{abstract}

Tel: 1-605-642-6920Ｅ-mail: mike.barnes@state.sd.us

Received: Nov. 21, 2019 Accepted: Dec. 12, 2019 Published: Dec. 16, 2019

doi:10.5296/ast.v8i1.16056 URL: https://doi.org/10.5296/ast.v8i1.16056

\begin{abstract}
Daily 15 -minute treatments of formalin at $1667 \mathrm{mg} / \mathrm{L}$ are typically used to prevent water mold infestations in coolwater fish eggs. This study evaluated the use of a reduced concentration of $834 \mathrm{mg} / \mathrm{L}$ during yellow perch Perca flavescens egg incubation until the eyed stage of egg development. No water mold was observed on the perch eggs using either formalin treatment regime. Median survival to the eyed stage of egg development was not significantly different between the treatments and approached $90 \%$. There was also no significant difference in egg survival to hatch. In addition, fry length at hatching, although relatively short overall, was not significantly different between the formalin treatment concentrations. The results of this study indicate that reducing daily 15-minute formalin concentration from 1667 to $834 \mathrm{mg} / \mathrm{L}$ during yellow perch egg incubation will not affect survival through hatch or larval length at hatching.
\end{abstract}

Keywords: yellow perch, Perca flavescens, egg incubation, formalin, hatch, fry length

\section{Introduction}

Water molds (fungi) of the family Saprolegniaceae, such as Saprolegnia diclina, are ubiquitous in freshwater and commonly infect fish eggs during hatchery incubation (Piper et 
al., 1982). Daily prophylactic treatments with formalin have proven to be effective at inhibiting fungal (water mold) growth (Soupir \& Barnes, 2006; Rach et al., 1997). Fungal infestations can become particularly problematic towards the end of yellow perch Perca flavescens egg incubation (Hart et al., 2006).

The results from experiments with formalin treatments on incubating percid eggs are far from uniform. Although Abd El-Gawad et al. (2015) and Hart et al. (2006) observed positive effects from treating perch eggs with relatively low formalin concentrations, Soupir and Barnes (2006) reported that formalin concentrations lower than $1667 \mathrm{mg} / \mathrm{L}$ resulted in reduced walleye (Sander vitreus) egg survival during hatchery incubation. However, formalin tolerance varies by species (Rach et al., 1997) and the use of concentrations greater than 1000 $\mathrm{mg} / \mathrm{L}$ for 15 min may reduce yellow perch egg survival (Abd El-Gawad et al., 2015). Some of the inconsistency with these results is likely due to differences in incubation water chemistry (Barnes et al., 2004).

In South Dakota, yellow perch are a highly sought-after sportfish (Longmire, 2019) and inconsistent natural recruitment in lakes has led to increased requests of hatchery-reared fish for supplemental stockings (Brown and St. Sauver, 2002). Historically, virulent water mold populations have required daily, 15-minunte formalin treatments of $1667 \mathrm{mg} / \mathrm{L}$ during egg incubation at Blue Dog State Fish Hatchery near Waubay, South Dakota, USA. However, the use of a lower formalin concentration has not been investigated for yellow perch and recent results indicate that concentrations greater than $1000 \mathrm{mg} / \mathrm{L}$ can reduce their egg survival (Abd El-Gawad et al., 2015). Thus, the objective of this study was to compare the effects of a reduced formalin concentration of $834 \mathrm{mg} / \mathrm{L}$ with the established standard of $1667 \mathrm{mg} / \mathrm{L}$ throughout yellow perch egg incubation on egg survival, hatching rate, fry length, and water mold control.

\section{Materials and Methods}

\subsection{Initial Egg Incubation}

Newly fertilized yellow perch eggs from Oakwood Lakes (Brookings County, South Dakota, USA) were received at Blue Dog Lake State Fish Hatchery on April 15, 2015. Eggs were divided into 20,100-mL samples, with each sample placed into an individual incubation tray (Flex-a-lite Consolidated, Tacoma, Washington, USA). Groups of five trays were vertically stacked, resulting in a total of four stacks. Each stack was a discrete flow through system. Formalin (Parasite-S; 37\% formaldehyde; Western Chemical, Inc., Ferndale, Washington, USA) was applied using a peristaltic pump (Thermo Fisher Scientific, Barrington, Illinois, USA) daily for $15 \mathrm{~min}$ until the eggs became eyed. Two stacks received formalin at $834 \mathrm{mg} / \mathrm{L}$ and two stacks received formalin at $1667 \mathrm{mg} / \mathrm{L}$. More than one stack was used per treatment to address potential stack variability. Each treatment was replicated ten times $(n=10)$ with the experimental unit being an individual tray. Each stack received $20.4 \mathrm{~L} /$ minute of filtered well water (temperature $=9.8{ }^{\circ} \mathrm{C}$; total hardness $=506 \mathrm{mg} / \mathrm{L} \mathrm{CaCO}{ }_{3}$; alkalinity $=264 \mathrm{mg} / \mathrm{L}$ $\mathrm{CaCO}_{3} ; \mathrm{pH}=7.5$; total dissolved solids $=612 \mathrm{mg} / \mathrm{L}$ ). 


\subsection{Determination of Egg Survival to Eyed Stage}

On April 29 at the eyed-stage of egg development, a transparent, 12-equal-square numbered grid the size of the incubation tray was placed in each tray. Egg samples varying from 1.3 to 3.9 grams were removed from four randomly selected grid-squares per tray. All eggs in the samples were identified as either viable or dead, and egg viability for an individual tray (replicate) was determined by taking the mean survival of the four samples. Because eyed-egg survival data failed the Kolmogorov-Smirnov test for normality $(P<0.10)$, a nonparametric Mann-Whitney $U$ test was used to compare survival between the treatments. Significance was predetermined at $P<0.05$.

\subsection{Egg Incubation to Hatch}

On April 30th, 1.9 to 3.2 g samples of presumably viable eyed eggs were removed from two trays (one per stack) of each treatment $(n=2)$. These eyed egg samples were placed on artificial vegetation in 3.78-L buckets filled with 2.0 - $\mathrm{L}$ of filtered well water $\left(9.8^{\circ} \mathrm{C}\right)$ and four buckets were used for each treatment. Artificial vegetation was used in place of natural so that the vegetation did not have to be periodically exchanged due to decomposition that may have also lowered dissolved oxygen concentrations. Data was averaged between buckets that contained eggs from the same tray, so that the experimental unit remained consistent (incubation tray). The number of fry that hatched along with water temperature and dissolved oxygen measurements were recorded daily. The water temperature in the buckets increased from 9.8 to $16{ }^{\circ} \mathrm{C}$ during each 24 -hour period, before returning $9.8{ }^{\circ} \mathrm{C}$ to begin the next 24-hour period. Dissolved oxygen ranged from 7.2 and $8.8 \mathrm{mg} / \mathrm{L}$ in all replicates.

\subsection{Determination of Survival to Hatch}

Hatched perch fry were collected by transferring the vegetation from the bucket to a temporary holding bucket containing filtered well water at the same temperature. The water from the study bucket was then poured through a brine shrimp net, to collect the fry. Immediately after collection, the fry were preserved in a $10 \%$ formalin solution. At a later date, all fry were counted, with a maximum of 10 from each daily sample measured for total length to the nearest $0.1 \mathrm{~mm}$. The study bucket was then refilled with filtered well water with the vegetation from the holding bucket returned. Any fry that hatched in the holding bucket were included in the daily fry count. After four days, hatching was complete and a small number of eyed eggs had expired in each bucket. The number of expired eggs was summed with the number of hatched fry to determine the beginning number of eyed eggs for each bucket. Because of the small sample size $(n=2)$ and associated risk of violating the assumption of normality, a non-parametric Mann-Whitney $U$ test was used to test for differences in cumulative hatching percentages and fry length with significance set at $P=$ 0.05 .

\section{Results}

Survival to the eyed stage of egg development was not significantly different between the formalin concentrations (Mann-Whitney $\mathrm{U}$ test stat $=0.910, \mathrm{df}=1, P=0.910$; Table 1). Eyed egg survival was nearly $90 \%$ for both formalin treatments. There was also no significant 
difference between the formalin treatments in hatching rates, which were over $98 \%$ for both formalin concentrations. The cumulative percent of hatched fry did not differ significantly at any date. Hatching started in both treatments on incubation day 17 and was completed by incubation day 20 (Table 2).

Table 1. Survival to the eyed stage of development of yellow perch eggs receiving daily, 15 -minute formalin treatments at either 834 or $1667 \mathrm{mg} / \mathrm{L}$

\begin{tabular}{cccc}
\hline & \multicolumn{3}{c}{ Egg Survival } \\
\cline { 2 - 4 } Formalin Concentration (mg/L) & Median & Minimum & Maximum \\
\hline 834 & 89.2 & 55.0 & 95.7 \\
1667 & 88.6 & 74.1 & 97.3 \\
\hline
\end{tabular}

Table 2. Cumulative hatching percentages of yellow perch eggs that had previously been treated with daily, 15-minute formalin treatments at either 834 or $1667 \mathrm{mg} / \mathrm{L}$ until the eyed stage of development, Incubation day is the number of days from the start of incubation

\begin{tabular}{clcccc}
\hline & \multicolumn{5}{c}{ Hatch $(\%)$} \\
\cline { 2 - 6 } Formalin $(\mathrm{mg} / \mathrm{L})$ & & Day 17 & Day 18 & Day 19 & Day 20 \\
\hline \multirow{2}{*}{834} & Median & 11.8 & 39.3 & 68.0 & 98.5 \\
& Range & $0.0-23.5$ & $37.0-41.5$ & $66.5-69.5$ & $98.0-99.0$ \\
\hline \multirow{2}{*}{1667} & Median & 27.3 & 61.8 & 75.5 & 99.0 \\
& Range & $18.0-36.5$ & $48.5-75.0$ & $63.5-87.5$ & $98.0-100.0$ \\
\hline
\end{tabular}

No significant differences were observed in the total length of hatched fry between concentrations at any date. Fry total lengths ranged from 3.9 to $4.9 \mathrm{~mm}$ and appeared to increase as incubation time increased (Table 3). Approximately $75 \%$ of the hatched fry in the $834 \mathrm{mg} / \mathrm{L}$ treatment, and $40 \%$ in the $1667 \mathrm{mg} / \mathrm{L}$ treatment, were less than $4.5 \mathrm{~mm}$. The longest fry at hatching were observed on the final day in both treatments.

Table 3. Fry total length $(\mathrm{mm})$ from yellow perch eggs that were treated with daily, 15-minute formalin treatments at either 834 or $1667 \mathrm{mg} / \mathrm{L}$ until the eyed stage of development. Incubation day is the number of days from the start of incubation

\begin{tabular}{clcccc}
\hline & \multicolumn{5}{c}{ Length $(\mathrm{mm})$} \\
\cline { 2 - 6 } Formalin $(\mathrm{mg} / \mathrm{L})$ & & Day 17 & Day 18 & Day 19 & Day 20 \\
\hline \multirow{2}{*}{834} & Median & 4.1 & 4.4 & 4.7 & 4.9 \\
& Range & $4.1-4.1$ & $4.3-4.4$ & $4.6-4.8$ & $4.8-5.0$ \\
\hline \multirow{2}{*}{1667} & Median & 3.9 & 4.1 & 4.2 & 4.7 \\
& Range & $3.9-3.9$ & $4.0-4.1$ & $4.2-4.2$ & $4.6-4.7$ \\
\hline
\end{tabular}




\section{Discussion}

The results of this study showing no decrease in survival associated with the highest formalin concentration differ from those seen by Abd El-Gawad et al. (2015). They reported that daily, 15 -min $1000 \mathrm{mg} / \mathrm{L}$ formalin treatments significantly decreased yellow perch egg survival compared to lowered formalin concentrations of 250 and $500 \mathrm{mg} / \mathrm{L}$. However, the Abd El-Gawad et al. (2015) study used higher water temperatures $\left(15.6\right.$ to $\left.17.5^{\circ} \mathrm{C}\right)$, than the $11^{\circ} \mathrm{C}$ used in this study. Higher water temperatures increase formalin toxicity (Piper et al., 1982). Formalin concentrations of greater than $500 \mathrm{mg} / \mathrm{L}$ have also been shown to increase fish egg incubation times (Akpoilih \& Adebayo, 2010; Abd El-Gawad et al., 2015). However, no differences in hatching times between formalin treatment concentrations in this study were observed. This may be because no concentrations below $500 \mathrm{mg} / \mathrm{L}$ were used. The relatively low incubation water temperature of $11^{\circ} \mathrm{C}$ may also have negated any possible formalin effects on the duration of egg incubation.

Yellow perch total length at hatching has been reported to range from 4.5 and $7.0 \mathrm{~mm}$ (Mansueti, 1964; Hokanson \& Kleiner, 1974; Clady, 1976; Ney, 1978). In this study, a large percentage of hatched fry were shorter than $4.5 \mathrm{~mm}$. This could be because the fry were preserved in formalin prior to measurement, which can result in reduced total lengths (Nordeide, 2019). The use of formalin or other preservatives in other studies documenting larval yellow perch length (Mansueti, 1964; Hokanson \& Kleiner, 1974; Clady, 1976; Ney, 1978) is unknown. Other possible explanations for the reduced size of larval perch observed in this study include maternal characteristics (Heyer at al., 2001; Raventos \& Planes, 2008), possible premature hatching due to physically moving the eggs (Hokanson \& Kleiner, 1974), and potential formalin toxicity during the early stages of yellow perch development (Abd El-Gawad et al., 2015). Because both starvation and predation of larval fishes are size dependent (Miller et al., 1988), subsequent survival of larval yellow perch with reduced size may be reduced. Also, with both formalin treatment concentrations used in this study, fry length was positively related to hatching time, suggesting that earlier hatched fry must undergo more development prior to first feeding in comparison to later hatched fry (Jordaan, 2002).

The egg survival and hatching rates reported in this study are comparable to that reported by Hart et al. (2006). They noted that yellow perch hatching rates routinely exceed $70 \%$. With survival to the eyed stage of egg development nearly $90 \%$, and with over $98 \%$ of the eyed eggs hatching, egg survival in this study was much greater than $70 \%$.

Because both formalin treatment concentrations used in this study controlled fungal growth, using only $834 \mathrm{mg} / \mathrm{L}$ instead of $1667 \mathrm{mg} / \mathrm{L}$ would reduce chemical costs, decrease the risk to worker health (Marking et al., 1994; Voorhees \& Barnes, 2016), and reduce potentially problematic formalin discharges into hatchery effluents (Masters, 2004). Formalin treatment concentrations of $834 \mathrm{mg} / \mathrm{L}$ have also been effective during the incubation of other percid eggs (Soupir \& Barnes 2006). Barnes and Soupir (2007) were also able to reduce formalin treatment concentrations from $1667 \mathrm{mg} / \mathrm{L}$ to $1000 \mathrm{mg} / \mathrm{L}$ during rainbow trout Oncorhynchus mykiss egg incubation with no impact on fungal growth or egg survival. 


\section{Al Macrothink}

Aquatic Science and Technology

ISSN 2168-9148

2020, Vol. 8, No. 1

The lower formalin concentration of $834 \mathrm{mg} / \mathrm{L}$ used in this study is also beneficial because the hatched perch fry were longer, although the small sample size makes definitive statements on the relationship between formalin and fry length difficult to state. Further experimentation with more replication and an assessment of fry quality is obviously needed. In addition, additional research is needed to determine the range of actual perch fry lengths, taking into consideration the impacts of preservation on length measurements. Lastly, other formalin treatment concentrations and treatment regimens on yellow perch eggs warrant further consideration, given the negative impacts of formalin use on yellow perch survival reported by Abd El-Gawad et al. (2015).

\section{Conclusions}

The results of this study indicate that formalin treatment concentrations can be reduced from the standard $1667 \mathrm{mg} / \mathrm{L}$ without any negative effects of yellow perch egg survival, while still controlling fungal growth. In addition, decreased formalin treatment concentrations may also be beneficial, if, as this study suggests, they do lead to the hatching of longer fry. Lastly, reductions in formalin usage by using lower concentrations provides both occupational health and environmental benefits.

\section{Acknowledgement}

Special thanks to Jerry Broughton, Randy Smidt, Ryan Rasmus, Nathan Pool, Joe Lucas, Collin Sherlock, and Ryan Reishus for fish culture duties and laboratory work that allowed for the publication of these data.

\section{References}

Abd El-Gawad, E. A., Shen, Z. G., \& Wang, H. P. (2015). Efficacy of formalin, iodine, and sodium chloride in improvement of egg hatching rate and fry survival prior to onset of exogenous feeding in yellow perch. Aquaculture Research, 47, 2461-2469. https://doi.org/10.1111/are.12694

Akpoilih, B. U., \& Adebayo, O. T. (2010). Effect of formalin on the hatching rate of eggs and survival of larvae of the African Catfish (Clarias gariepinus). Journal of Applied Sciences and Environmental Management, 14, 31-34. https://doi.org/10.4314/jasem.v14i4.63252

Barnes, M. E., \& Soupir, C. A. (2007). An evaluation of selected formalin and hydrogen peroxide treatment regimes on rainbow trout eyed eggs. North American Journal of Aquaculture, 69, 5-10. https://doi.org/10.1577/A05-080.1

Barnes, M. E., Gabel, A. C., Durben, D. J., Hightower, T. R., \& Berger, T. J. (2004). Changes in water hardness influence colonization of Saprolegnia diclina. North American Journal of Aquaculture, 66, 222-227. https://doi.org/10.1577/A03-058.1

Brown, M. L., \& St. Sauver, T. R. (2002). An assessment of yellow perch, Perca flavescens, stocking contributions in eastern South Dakota Lakes. Fisheries Management and Ecology, 9, 225-234. https://doi.org/10.1046/j.1365-2400.2002.00299.x 
Clady, M. D. (1976). Influence of temperature and wind on the survival of early stages of yellow perch, Perca flavescens. Journal of Fisheries Research Board of Canada, 33, 1887-1893. https://doi.org/10.1139/f76-241

Hart, S. D., Garling, D. L., \& Malison. J. A. (2006). Yellow Perch Culture Guide. NCRAC Culture Series 103. North Central Regional Aquaculture Center Publications Office, Iowa State University, Ames.

Heyer, C.J. et al. (2001). Maternal effects as a recruitment mechanism in Lake Michigan yellow perch (Perca flavescens). Canadian Journal of Fisheries and Aquatic Sciences, 58, 1477-1487. https://doi.org/10.1139/f01-090

Hokanson, K. E. F., \& Kleiner, C. F. (1974). Effect of constant and rising temperature on survival and developmental rates of embryonic and larval yellow perch, Perca flavescens (Mitchill). In J.H.S. Blaxter (Ed.), The Early Life History of Fish (pp.437-448). Springer-Verlag, New York. https://doi.org/10.1007/978-3-642-65852-5_36

Jordaan, A. (2002). The effect of temperature on the development, growth, and survival of Atlantic cod (Gadus morhua) during early life-histories. Electronic Theses and Dissertations 141. http://digitalcommons.library.umaine.edu/etd/141

Longmire, C. L. (2019). Report of Results: 2017 South Dakota Angler Survey. Pierre, SD: South Dakota Game, Fish and Parks.

Mansueti, A. J. (1964). Early development of the yellow perch, Perca flavescens. Chesapeake Science, 5, 46-66. https://doi.org/10.2307/1350790

Marking, L. L., Rach, J. J., \& Schreier, T. M. (1994). Evaluation of antifungal agents for fish culture. Progressive Fish Culturist, 56, 225-231.

https://doi.org/10.1577/1548-8640(1994)056<0225:AFSEOA>2.3.CO;2

Masters, A. L. (2004). A review of methods for detoxification and neutralization of formalin in water. North American Journal of Aquaculture, 66, 325-333.

https://doi.org/10.1577/A03-060.1

Miller, T. J., Crowder, L. B., Rice, J. A., \& Marschall, E. A. (1988). Larval size and recruitment mechanisms in fishes: toward a conceptual framework. Canadian Journal of Fisheries and Aquatic Sciences, 45, 1657-1670. https://doi.org/10.1139/f88-197

Ney, J. J. (1978). A synoptic review of yellow perch and walleye biology. In R. L. Kendall (Ed.), Selected coolwater fishes of North America (pp. 1-12). Special Publication No. 11, American Fisheries Society, Washington, D.C.

Nordeide, J. T. (2019). Accuracy of body mass estimates of formalin-preserved fish - a review. Journal of Fish Biology doi:10.1111/jfb.14146. https://doi.org/10.1111/jfb.14146

Piper, R. G., McElwain, I. B., Orme, L. E., McCraren, J. P., Fowler, L. G., \& Leonard, J. R. (1982). Fish Hatchery Management. U.S. Fish and Wildlife Service, Washington, D.C.

Rach, J. J., Howe, G. E., \& Schreier, T. M. (1997). Safety of formalin treatments on warmand coolwater fish eggs. Aquaculture, 149, 183-191.

https://doi.org/10.1016/S0044-8486(96)01447-0

Raventos, N., \& Planes, S. (2008). Maternal size effects on early life traits on the temperate fish Symphodus roissali. Aquatic Biology, 4, 1-6. https://doi.org/10.3354/ab00086 
Soupir, C. A., \& Barnes, M. E. (2006). Reduced formalin and hydrogen peroxide treatments during walleye egg incubation. North American Journal of Aquaculture, 68, 276-280. https://doi.org/10.1577/A05-037.1

Voorhees, J. M., \& Barnes, M. E. (2016). Airborne formaldehyde levels during simulated formalin egg treatments in vertical-flow tray incubators at a production fish hatchery. Journal of Agricultural Safety and Health, 22, 199-207. https://doi.org/10.13031/jash.22.11791

\section{Copyrights}

Copyright for this article is retained by the author(s), with first publication rights granted to the journal.

This is an open-access article distributed under the terms and conditions of the Creative Commons Attribution license (http://creativecommons.org/licenses/by/4.0/) 